\section{Prospects for women in science}

SIR - Your recent leading article on women in science ${ }^{1}$ reflects insensitivity to the problems women face in science, in marked contrast to recent leading articles in Science ${ }^{2}$ and in the Lancet $^{3}$. The assumption in your leading article and in a recent report from the Max Planck Society ${ }^{4}$ is that the only problems stopping women making it to the top in science are child care and long working hours. This one-sided emphasis is an intellectual insult to those women with or without children - who are already working more than 40 hours a week and are striving to make an independent career in science. Such women share with the writer of the leading article the belief that "there is no evidence that sex is related to success in scientific research" and are prepared to be judged by the same objective standards as their male colleagues. However, in return, women have the right to demand the same job opportunities and the same resources, and to enjoy the same privileges as are given to men at similar stages in their careers. Women in science can face prejudice that may be "entirely unintentional" but is nevertheless real, and should not be comforted with the statement that "there is no doubt that fewer women than men are among those at the top of their profession and that this situation should change with the changing numbers of women in the workplace". Of course it should but will it?

For instance, only 2 of 210 directors (or heads of research groups) in the Max Planck Society (MPG) are female (although it should be noted that the only female director in the natural sciences has won the Lasker award). One cannot apply for a vacant position as an MPG director, and although the system used to select new directors has obvious advantages in choosing fields and selecting able individuals, a figure of 1 per cent suggests that women are not properly considered. In addition, the trend in the MPG to establish theme institutes rather than select the best individuals regardless of field further discriminates against women, as women who might be considered as directors are not distributed equally over all fields.

In 1991 the MPG used positive action to establish 29 five-year groups in the former East Germany and all are headed by men. Women are also poorly represented in the German scientific academies - the Bavarian Academy of

\footnotetext{
Letters submitted for Correspondence should be typed, double-spaced, on the side of the paper only.
}

Sciences, for example, had in 1991 not only no female member but had had none for at least the past ten years. Should one really accept the implicit but instances not a single woman can be found without lowering the current standards? Is such an argument tenable in a profession that otherwise prides itself on objectivity of judgement and international standards? Or does it merely reflect a desire to preserve the status quo?

A serious effort to improve the situation in Germany or elsewhere has to approach the problem at two levels. On the one hand ways have to be found to identify and appoint qualified women to top positions, and to set and publicize realistic short-term goals (not quotas) to increase the number of women at the top who participate in decision-making processes and who act also as role models. As shown by experience in the United States, this can be done without a decrease in standards. On the other hand, positive action should be used for a limited time at a lower level to increase from which future holders of top positions - be it in research institutes, in universities, or in industry - can emerge. One way might be to finance starting scientist positions that are preferentially given to women and which could be held for five years in a laboratory of the individual's choice. This would give more women sufficient resources, time and self-confidence to develop their own research programmes at a critical point ${ }^{5}$ in their careers. The Habilitation Program of the Deutsche Forschungsgemeinschaft, which is preferentially aimed at women and which also includes some funds for child care, is a step in the right direction. Other measures that force consideration of whether there are qualified women whether for speakers at a meeting as in the case of the National Science Foundation, for a tenured appointment as at good universities in the United States for the past 20 years, or on committees for evaluation of institutes or departments - can only be welcomed as they draw attention to an imbalance that is at best a long way from being solved ${ }^{6}$, and at worst, at least in Europe, is too often swept under the carpet and ignored.

\section{Mary Osborn}

Max Planck Institute

for Biophysical Chemistry,

W34 Goettingen, Germany

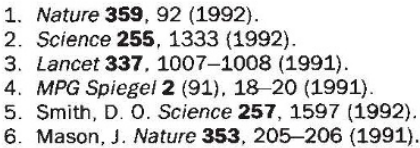

Nature 359, 92 (1992)

Science 255, 1333 (1992)

Lancet 337, 1007-1008 (1991).

Smith, D. O. Science 257, 1597 (1992)

6. Mason, J. Nature 353, 205-206 (1991) never stated argument that in all these the pool of qualified female scientists
Altered food

SIR - It is unfortunate to encounter evidence of more silliness about new biotechnology applied to food ("Chefs forswear genetically altered food," $\mathrm{Na}$ ture 359, 8; 1992). Perhaps as scientists we take the prospect of "new biotech" or "genetically engineered" foods for granted because they are so obviously refinements of the older ones that have been with us for so long. Yeast has been used to brew beer for eight millennia, and farmers were crossbreeding livestock long before Mendel's experiments helped to define the principles of genetics. For decades, genes have been transferred from one species to another and even from one genus to another to yield commonly available food plants including oats, rice, currants, potatoes, tomatoes, wheat and corn (Goodman et al. Science 236, 48; 1987). These plants, resulting from wide crosses made possibly by embryo rescue techniques, are "genetically engineered" and even "transgenic" by any reasonable scientific definition. They are found not just in laboratories or test plots but are the very same fruits, vegetables and grains sold at the local supermarket. The recombinant DNA and related techniques of the "new biotechnology" essentially speed up and increase the precision of gene transfer.

Far from eliciting concern, the use of more precise techniques that yield a better-characterized and more predictable plant variety should be seen as potentially positive. It was therefore surprising to see a group of chefs, of all people, resisting further improved varieties. Undoubtedly, much of the nonscientists' uncertainty about biotechnology results from a lack of perspective on its pedigree; would they boycott the genetic hybrid of tangerine and grapefruit that we call a "tangelo"? Or the mutant peaches we call "nectarines"?

If a few sadly exploited chefs really do intend to make do with "non-genetically engineered" foods, their menu is likely to be a singular one, offering little more than fish, shellfish and wild game and berries. I'll order from the Menu de Degustation de Genetechnologie, thank you very much.

Henry I. Miller

Office of Biotechnology,

Food and Drug Administration,

Rockville, Maryland 20867, USA

SIR - Jeremy Rifkin's Foundation on Economic Trends is shortsighted in its campaign against genetically engineered foods.

I plan to boycott restaurants that display the Pure Foods Campaign logo.

Joseph J. Brigham

3103 Coriander Drive,

New Bern, North Carolina 28562, USA 